\title{
Co-seismic grace gravity-based 11-layered 3-D thrust fault model for the Sumatra earthquake 2004
}

\author{
Rambhatla G Sastry* and Mahendra Kumar Sonker \\ Department of Earth Sciences, Indian Institute of Technology Roorkee, Roorkee, Uttarakhand 247 667, India. \\ *Corresponding author.e-mail: rgss1fes@iitr.ac.in rgssastry@gmail.com
}

MS received 24 May 2017; revised 20 April 2018; accepted 30 April 2018;

published online 19 January 2019

Our co-seismic Gravity Recovery and Climate Experiment gravity data (level 2 'RL_05' data product 'GX-OG-_2-GSM) for the Sumatra earthquake 2004 is obtained by differencing monthly gravity field average for November 2004 from that of January 2005 and band-pass filtering $\left(17-30^{\circ}\right.$ and orders) in the spectral domain. Here, we propose a 11-layered three-dimensional (3-D) thrust fault gravity model based on different co-seismic rupture models in the literature. It honours co-seismic deformation of the ocean surface, ocean bottom and subsurface earth medium, different earthquake parameters and hypocentre information ( $\sim 35 \mathrm{~km}$ below mean sea level). Our forward gravity response matches well with the observed gravity (RMS error of $0.06257 \mu \mathrm{gal}(6.26 \%)$ ) data and our model allowed an independent computation of rupture length, instantaneous velocity, average seismic moment and momentum, which are, respectively, $1560 \mathrm{~km}, 2.9 \mathrm{~km} / \mathrm{s}, 4.53 \times 10^{22} \mathrm{Nm}$ and $9.7 \times 10^{17} \mathrm{~kg} \mathrm{~m} / \mathrm{s}$. These parameters fairly agree with those in the literature. The computed momentum indeed corresponds to an area pulse $\left(9.7 \times 10^{17} \mathrm{~kg} \mathrm{~m} / \mathrm{s}\right)$ at ocean bottom that led to a tsunami generation. Thus, the proposed multi-layered 3-D gravity model in traditional fashion fully accounts for co-seismic gravity signal of the Sumatra earthquake 2004.

Keywords. GRACE satellite gravity; spherical harmonics; 3-D thrust fault model; co-seismic gravity anomaly.

\section{Introduction}

Global gravity monitoring through satellite gravity has received a big boost with the Gravity Recovery and Climate Experiment (GRACE) (Cazenave and Chen 2010). Important GRACE applications include seismic characterisation of offshore tsunami-genic mega-thrust earthquakes including 2004 Sumatra earthquake (Tapley et al. 2004; Han et al. 2006; De Viron et al. 2008; Heki and Matsuo 2010; Broerse et al. 2011; Simons et al. 2011; Wang et al. 2012a; Broerse et al. 2014). In midlatitudes, the approximate spatial resolution of
GRACE works out to be a circle of radius of $300 \mathrm{~km}$ (Zlotnicki, private communication) and it facilitates GRACE gravity's sensitivity to near-surface rupture processes of major offshore earthquakes.

Mega-thrust ruptures (Chile earthquake 1960 and Alaska earthquake 1964) and the associated crustal deformation at a convergent boundary leading to a mass re-distribution was initially tackled by Plafker (1972). Seismic history prior to the Sumatra earthquake 2004 was contributed by several workers (Lay et al. 2005; Engdahl et al. 2007; Katsumata 2015). Using different data sources, the co-seismic slip distribution of the Sumatra 
earthquake 2004 was inferred by several workers (Ammon et al. 2005; Banerjee et al. 2005; Lay et al. 2005; Vigny et al. 2005; Subarya et al. 2006; Chlieh et al. 2007). Post-earthquake activity was also studied extensively (Araki et al. 2006; Briggs et al. 2006; Rhie et al. 2007; Sibuet et al. 2007; Konca et al. 2008).

The magnitude of the Sumatra earthquake 9.3 on 26 December, 2004 has resulted in a tsunami, which has caused great damage (Sumatra earthquake 2004 Wikipedia) when the Indian Plate was subducted by the Burma Plate. The epicentre of the Sumatra earthquake 2004 was $3.316^{\circ} \mathrm{N}$ and $95.854^{\circ} \mathrm{E}$ with a rupture length of $1300 \mathrm{~km}$ and hypocentre at $35 \mathrm{~km}$ (Lay et al. 2005; Engdahl et al. 2007; Katsumata 2015) below mean sea level (msl). It had a fault length more than $1300 \mathrm{~km}$ extending from $2^{\circ}$ to $14^{\circ} \mathrm{N}$ with $10 \mathrm{~m}$ fault slip along the Sumatra-Andaman trough (Ammon et al. 2005; Lay et al. 2005; Vigny et al. 2005; Wang and Liu 2006; Chlieh et al. 2007; Rhie et al. 2007, Shearer and Bürgmann 2010). In offshore northern Sumatra, the plate motion is estimated (Socquet et al. 2006; Delescluse and ChamotRooke 2007 ) to be $47 \mathrm{~mm} / \mathrm{yr}$ up to $004^{\circ} \mathrm{N}$, and in northernmost Sumatra the motion along the right lateral Sumatra Fault is $25 \mathrm{~mm} / \mathrm{yr}$ (Sieh and Natawidjaja 2000). The rupture length and slip distribution are addressed by Lay et al. (2005) and Poisson et al. (2011). Liu et al. (1998) have simulated the Sumatra tsunami generation and propagation.

Earlier elastic gravity modelling efforts include radially stratified earth model (Gilbert and Backus 1968), faulting on a finite rectangular plane buried in a homogeneous half-space that of Okubo (1992), dislocation in spherically symmetric earth model (Sun and Okubo 1993, 1998) and layered spherical earth involving spherical harmonic expansion (Pollitz 1997, 2011). Sun and Okubo's formulations (Sun and Okubo 1993, 1998) have initiated novel satellite gravity modelling, stress evolution and time-displacement models for simulated slip histories (Hayes et al. 2006; Harms et al. 2015). One- and two-dimensional fault models have been proposed by Wang et al. (2012b) and Barckhausen (2006) have dealt with the detailed magnetic anomaly map of the 2004 Sumatra earthquake. Using the sea level equation method, Broerse et al. (2014) have modelled the geoid undulation owing to ocean water movement initiated by co-seismic vertical and horizontal deformations of the sea floor of mega-thrust earthquakes. However, geoid undulations can also be inferred from standard geodetic methods (Heiskanen and Moritz 1967; Lambeck 1990). Sastry and Sonker (2017) have outlined the GRACE gravity-based gravity model for 2011 Japan earthquake.

Recently, Gokula and Sastry (2015a,b) have derived the forward gravity analytic expression for a three-dimensional (3-D) vertical pyramid model and demonstrated its flexibility through several numerical experiments and a case study. The model is quite flexible enough for modelling subduction zone tectonics.

A comprehensive traditional co-seismic 3-D gravity models honouring ocean surface deformation, ocean bottom (thrust fault tectonics) upheaval and subsurface deformation duly constrained by seismological data and inferences are rare in the literature. So, we address this scientific gap through 3-D gravity modelling (11-layered thrust fault) based on a unit vertical pyramid model of Gokula and Sastry (2015a,b) for co-seismic gravity signal of the Sumatra earthquake 2004. Our model also infers rupture length, average instantaneous velocity, seismic moment and momentum of this mega-earthquake independently and these estimates match fairly well with the published literature.

We deal introduction in section 1 , theory in section 2, data processing and methodology including estimation of instantaneous velocity, seismic moment and seismic momentum aspects in section 3 , results in section 4 , the detailed discussion in section 5 and conclusions in section 6 .

\section{Theory}

Gravitational potential and its gradient are calculated from the spherical harmonic coefficients $\left(90^{\circ}\right.$ and orders) for Sumatra earthquake 2004 from the following expressions:

$$
\begin{aligned}
& V(r, \theta, \varphi) \\
& =\frac{G M}{R+h} \sum_{n=0}^{N} \frac{1}{r^{n+1}} \sum_{m=0}^{n}\left[a_{n m} P_{n m} \cos \theta \cos (m \varphi)\right. \\
& \left.\quad+b_{n m} P_{n m} \cos \theta \sin (m \varphi)\right] .
\end{aligned}
$$

The satellite gravity is described by the following spherical harmonic expression: 


$$
\begin{aligned}
& \nabla V(r, \theta, \varphi)=\frac{G M}{(R+h)^{2}} \\
& \quad \times \sum_{n=0}^{N} \frac{(n+1)}{r^{n+2}} \sum_{m=0}^{n}\left[a_{n m} P_{n m} \cos \theta \cos (m \varphi)\right. \\
& \left.\quad+b_{n m} P_{n m} \cos \theta \sin (m \varphi)\right]
\end{aligned}
$$

where $r=R /(R+h)$.

$a_{n m}$ and $b_{n m}$ are the spherical harmonic coefficients of degree $n$ and order $m$ and $P_{n m}$ are the Legendre's spherical functions. $\theta$ and $\varphi$ are the colatitude and longitude of a station, respectively, and $N=90$.

\section{Data and methodology}

In the present study, we use GRACE gravity data (level 2 'RL_05' data product 'GX-OG-_2-GSM') (Bettadpur 2007) in the form of spherical harmonic coefficients up to a maximum of $90^{\circ}$ and orders. Broad steps of our methodology are as follows:

(1) Computation of gravity potential (spherical harmonic synthesis) for pre- and post-earthquake (tsunami) using spherical harmonic coefficients available in the public domain (http://isdc.gfz-potsdam.de) using equation (1) and thereby the gravity anomaly distribution for both episodes.

(2) Estimation of differential (tsunami-genic) gravity data by differencing pre- (November 2004) from post- (January 2005) gravity anomaly distribution (red contour) for different bandpass filter options of spherical harmonic coefficients.

(3) Check for a proper band-pass filter $\left(17-30^{\circ}\right.$ and orders) to yield co-seismic gravity signal (figure 1).

(4) Framing a 3-D 11-layered gravity model based on available geophysical constraints in the published literature. The co-seismic top sea water layer deformation can be computed using geoidal height variation (Heiskanen and Moritz 1967; Lambeck 1990) for both pre- and post-earthquake events.

(5) The geoidal height $N=T / \gamma$, where $T$ and $\gamma\left(=G M / R^{2}\right)$ are, respectively, the disturbing potential and normal gravity on spherical earth.

(6) A 3-D forward gravity modelling for Sumatra earthquake 2004 source region using a unit vertical pyramid model (Gokula and Sastry $2015 \mathrm{a}, \mathrm{b})$.

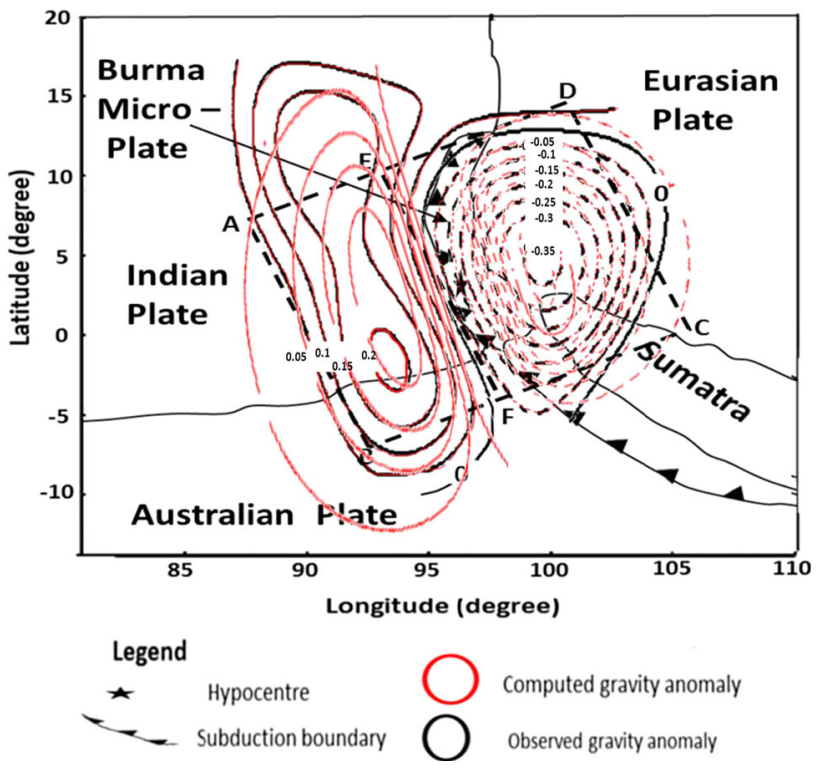

Figure 1. Our isolated GRACE satellite gravity map with superimposed 3-D forward gravity model response at a mean satellite height of $500 \mathrm{~km}$ above msl with a relevant background tectonic map of the 2004 Sumatra earthquake. The background tectonic map depicts Indian, Eurasian, Australian and Burma micro-plate boundaries. Epicentre of the 2004 Sumatra earthquake is also shown. Bold zero anomaly contour delineates the fault trace. The solid and dashed contours outline positive and negative gravity responses of our model (red) and observed (black) gravity anomalies. Gravity anomaly values are in the range -0.35 to $0.20 \mu$ gal. The root-mean-square (RMS) error deviation of computed gravity response with that of the observed gravity is $0.06257 \mu$ gal $(6.26 \%)$.

(7) Estimation of instantaneous velocity, seismic moment and seismic momentum on the basis of excess mass derivable from step (4) above.

\subsection{Instantaneous velocity computation}

Instantaneous velocity is the speed at a given moment of a wavefront in the direction of energy propagation (Sheriff and Stickney 1984). We equate the total energy (www.alabamaquake.com/energy. html) released for an earthquake of magnitude, M9.0 is treated as kinetic energy, which in turn is related to excess mass and instantaneous velocity. The excess mass of our model can be worked out from arrived model parameters from figure 2 and using equations (3) for a unit pyramid model and equation (4), respectively. Then, one can estimate the instantaneous velocity using kinetic energy given by equation (5).

The volume, $V$, of a vertical pyramid of height $h$, with top and bottom surfaces, $A 1$ and $A 2$, is 


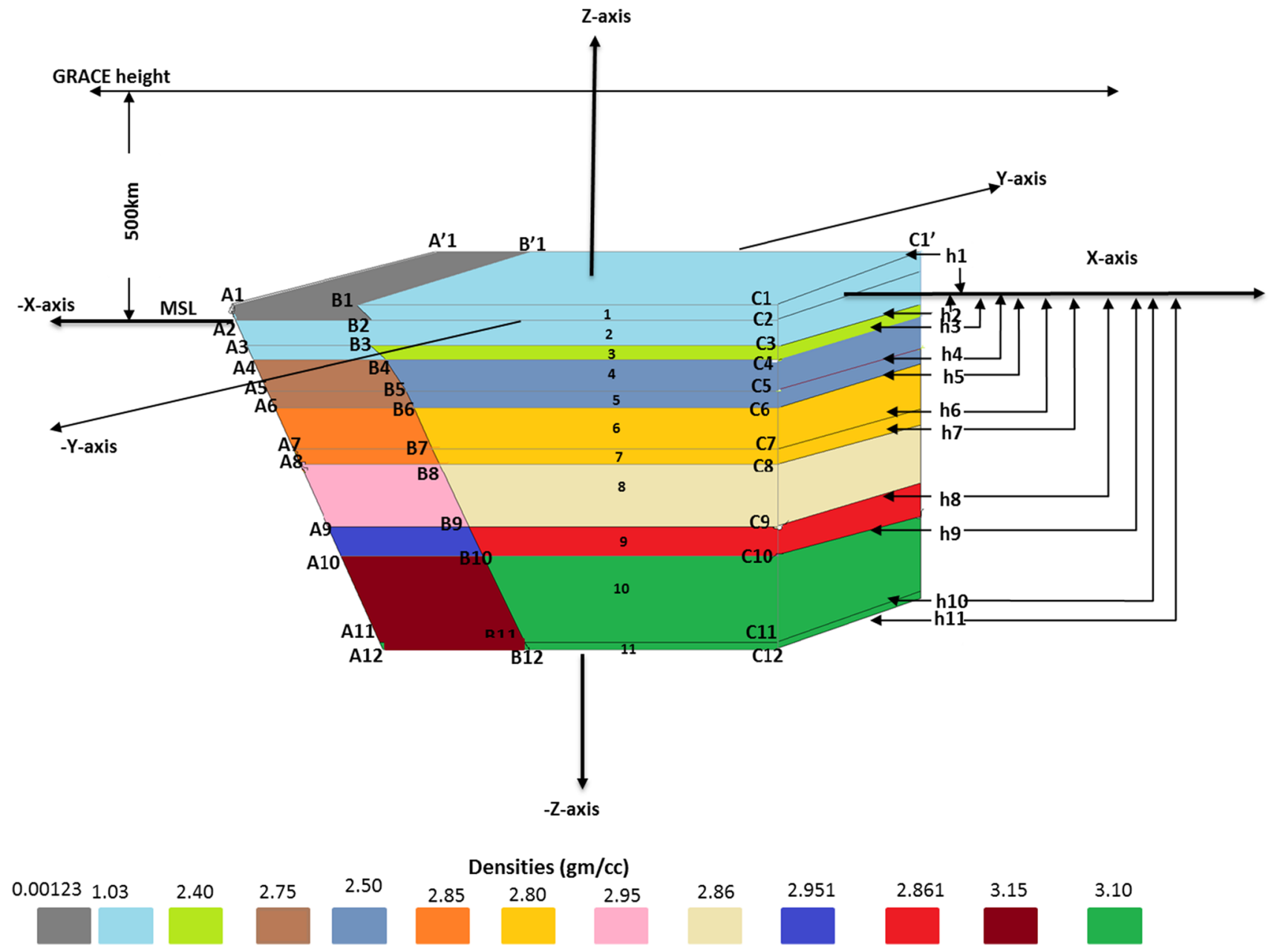

Figure 2. This schematic diagram explains our gravity model (dimensions and bulk densities). The unit model is a pyramid, whose analytical gravity response is provided by Gokula and Sastry (2015a, b). Numerals 1-5, respectively, refer to different layers in our gravity model. Dip angles $\theta_{1}=10^{\circ}, \theta_{2}=12^{\circ}, \theta_{3}=25^{\circ}, \theta_{4}=27^{\circ}, \theta_{5}=35^{\circ}, \theta_{6}=37^{\circ}, \theta_{7}=45^{\circ}, \theta_{8}=48^{\circ}, \theta_{9}=$ $55^{\circ}$ and $\theta_{10}=58^{\circ}$. The total forward gravity responses of layers $1,3,5,7,9$ and 11 constitute the computed gravity shown in red colour in (a). The pyramid vertices in different layers are as follows: $A 1\left(-37.510,-780,1.0 \times 10^{-6}\right) ; A 2(-37.500,-780,0)$; $A 3(-37.490,-780,-1.222) ; A 4(-37.470,-780,-1.226) ; A 5(-28.470,-780,-9.226) ; A 6(-28.460,-780,-9.332) ; A 7(-23.455$, $-780,-17.232) ; \quad A 8(-23.440,-780,-17.239) ; \quad A 9(-20.440,-780,-35.00) ; \quad A 10(-20.430,-780,-35.010) ; \quad A 11(-15.430$, $-780,-54.998) ; A 12(-15.420,-780,55.00) ; A 1^{\prime}\left(-37.510,780,1.0 \times 10^{-6}\right) ; A 2^{\prime}(-37.500,780,0) ; A 3^{\prime}(-37.490,780,-1.222)$; $A 4^{\prime}(-37.470,780,-1.226) ; A 5^{\prime}(-28.470,780,-9.226) ; A 6^{\prime}(-28.460,780,-9.332) ; A 7^{\prime}(-23.455,780,-17.232) ; A 8^{\prime}(-23.440$, $780,-17.239) ; \quad A 9^{\prime}(-20.440,780,-35.000) ; \quad A 10^{\prime}(-20.430,780,-35.010) ; \quad A 11^{\prime}(-15.430,780,-54.998) ; \quad A 12^{\prime}(-15.420$, $780,55.00) ; B 1\left(-13.510,-780,1.0 \times 10^{-6}\right) ; B 2(-13.500,-780,0) ; B 3(-13.490,-780,-1.222) ; B 4(-13.470,-780,-1.226)$; $B 5(-5.470,-780,-9.226) ; B 6(-5.460,-780,-9.332) ; B 7(-3.455,-780,-17.232) ; B 8(-3.440,-780,-17.239) ; B 9(-2.440$, $-780,-35.000) ; \quad B 10(-2.430,-780,-35.010) ; \quad B 11(-1.430,-780,-54.998) ; \quad B 12(-1.420,-780,55.000) ; \quad B 1^{\prime}(-13.510$, $\left.-780,1.0 \times 10^{-6}\right) ; B 2^{\prime}(-13.500,-780,0) ; B 3^{\prime}(-13.490,-780,-1.222) ; B 4^{\prime}(-13.470,-780,-1.226) ; B 5^{\prime}(-5.470,-780$, $-9.226) ; \quad B 6^{\prime}(-5.460,-780,-9.332) ; \quad B 7^{\prime}(-3.455,-780,-17.232) ; \quad B 8^{\prime}(-3.440,-780,-17.239) ; \quad B 9^{\prime}(-2.440,-780$, $-35.000) ; B 10^{\prime}(-2.430,-780,-35.010) ; B 11^{\prime}(-1.430,-780,-54.998) ; B 12^{\prime}(-1.420,-780,55.00) ; C 1(-2.168,-780,1.0 \times$ $\left.10^{-6}\right) ; C 2(-2.168,-780,0) ; C 3(-2.168,-780,-1.222) ; C 4(-2.168,-780,-1.226) ; C 5(-2.168,-780,-9.226) ; C 6(-2.168$, $-780,-9.332) ; C 7(-2.168,-780,-17.232) ; C 8(-2.168,-780,-17.239) ; C 9(-2.168,-780,-35.000) ; C 10(-2.168,-780$, $-35.010) ; C 11(-2.168,-780,-54.998) ; C 12(-2.168,-780,55.000) ; C 1^{\prime} \quad\left(-2.168,780,1.0 \times 10^{-6}\right) ; C 2^{\prime}(-2.168,780,0)$; $C 3^{\prime}(-2.168,780,-1.222) ; C 4^{\prime}(-2.168,780,-1.226) ; C 5^{\prime}(-2.168,780,-9.226) ; C 6^{\prime}(-2.168,780,-9.332) ; C 7^{\prime}(-2.168,780$, $-17.232) ; C 8^{\prime}(-2.168,780,-17.239) ; C 9^{\prime}(-2.168,780,-35.00) ; C 10^{\prime}(-2.168,780,-35.010) ; C 11^{\prime}(-2.168,780,-54.998)$; $C 12^{\prime}(-2.168,780,55.00)$; coordinates are expressed in $\mathrm{km}$. (b) Depths of the layers: $h_{1}=\left(1.0 \times 10^{-7}\right) \mathrm{km} ; h_{2}=(-1.222) \mathrm{km}$; $h_{3}=(-1.226) \mathrm{km} ; h_{4}=(-9.226) \mathrm{km} ; h_{5}=(-9.232) \mathrm{km} ; h_{6}=(-17.232) ; h_{7}=(-17.239) \mathrm{km} ; h_{8}=(-35.0000) \mathrm{km} ;$ $h_{9}=(-35.010) \mathrm{km} ; h_{10}=(-54.998) \mathrm{km} ; h_{11}=(-55.00) \mathrm{km}$; assumed average satellite height from mean sea level $(\mathrm{msl})$ is $500 \mathrm{~km}$. 
Table 1. GRACE gravity datasets used by previous authors compared to us.

\begin{tabular}{ll}
\hline Authors & \multicolumn{1}{c}{$\begin{array}{c}\text { GRACE datasets considered } \\
\text { (monthly average spherical } \\
\text { harmonic coefficients })\end{array}$} \\
\hline Our attempt & \multicolumn{1}{c}{$\begin{array}{c}\text { November 2004-January 2005 } \\
\text { Broerse } \text { et al. }(2011)\end{array}$} \\
Cazenave and Chen (2010) & $\begin{array}{l}\text { Two years before and after the earthquake } \\
\text { (2002-2006) }\end{array}$ \\
De Viron et al. $(2008)$ & July 2002-June 2007 \\
Panet et al. $(2007)$ & January 2004-January 2005 \\
Chen et al. $(2007)$ & January 2003-September 2006 \\
Han et al. $(2006)$ & April 2002-September 2012 \\
\hline
\end{tabular}

given by

$$
V=\frac{1}{3} \times h \times(A 1+A 2+\sqrt{A 1 \times A 2}) .
$$

Given the density contrast of the above pyramid to be $\Delta \sigma$, then excess mass, $M$, is given by

$$
M=\Delta \sigma \times V .
$$

Kinetic energy, $K_{e}$, associated with instantaneous velocity, $v$, is given by

$$
K_{e}=\frac{1}{2} M v^{2}
$$

\subsection{Seismic momentum estimation}

As per definition, the (instantaneous) seismic momentum is a product of mass and instantaneous velocity. However, in conventional seismology, this parameter is not used. It could be of interest in offshore tsunamigenic earthquake studies.

\subsection{Seismic moment estimation}

The scalar seismic moment, $M_{0}$, is defined by $M_{0}=\mu S D$, where $\mu$ is the shear modulus of the rocks involved in the earthquake, $S$ is the area (in $\mathrm{m}^{2}$ ) of rupture along the geologic fault where the earthquake occurred and $D$ (in $\mathrm{m}$ ) is the average displacement on $A$ (Stork et al. 2014).

\section{Results}

By using steps 1-6 of earlier mentioned methodology, we arrived at the isolated input gravity anomaly distribution (black colour contours in figure 1). Our method of isolation of anomaly is compared with alternative approaches in the literature (table 1). By considering the seismological constraints (tables 2 and 3), steps 4 and 5 of our methodology and thrust fault model details of Sibuet et al. (2007), we have framed a 3-D gravity forward model (figure 2). For this gravity model, the total gravity response (red coloured contours in figure 1) has been calculated by using a unit vertical pyramid model (Gokula and Sastry $2015 \mathrm{a}, \mathrm{b})$. The detailed forward gravity responses of 11-layered gravity model are included in figure 3 . The RMS error between observed and computed gravity is $0.06257 \mu$ gal $(6.26 \%)$ (figure 1), reflecting a fairly good match.

The implementation of step 6 of our methodology has yielded instantaneous velocity, rupture length, scalar seismic moment and momentum of the Sumatra earthquake 2004.

Arrived seismic moment is $4.53 \times 10^{22} \mathrm{Nm}$ for a shear modulus in the range $30 \mathrm{GP}$ (Geist et al. 2007). The computed instantaneous velocity, rupture length and momentum for the displaced actual mass of our model are, respectively, $2.9 \mathrm{~km} / \mathrm{s}$, $1560 \mathrm{~km}$ and $9.7 \times 10^{17} \mathrm{kgm} / \mathrm{s}$ with the inherent assumption of a total seismic moment energy $1.099 \times 10^{23} \mathrm{~J}$ associated with an earthquake of magnitude 9.3 (www.alabamaquake.com/energy. html).

\section{Discussion}

\subsection{General}

Contrary to current practice in the literature, our entire gravity modelling is based on isolated gravity signal (as per outlined methodology) at satellite height.

In table 1, we compare the different GRACE gravity data isolation procedures adopted by various authors including us. A close scrutiny of table 1 reveals that our dataset is indeed the closest one 


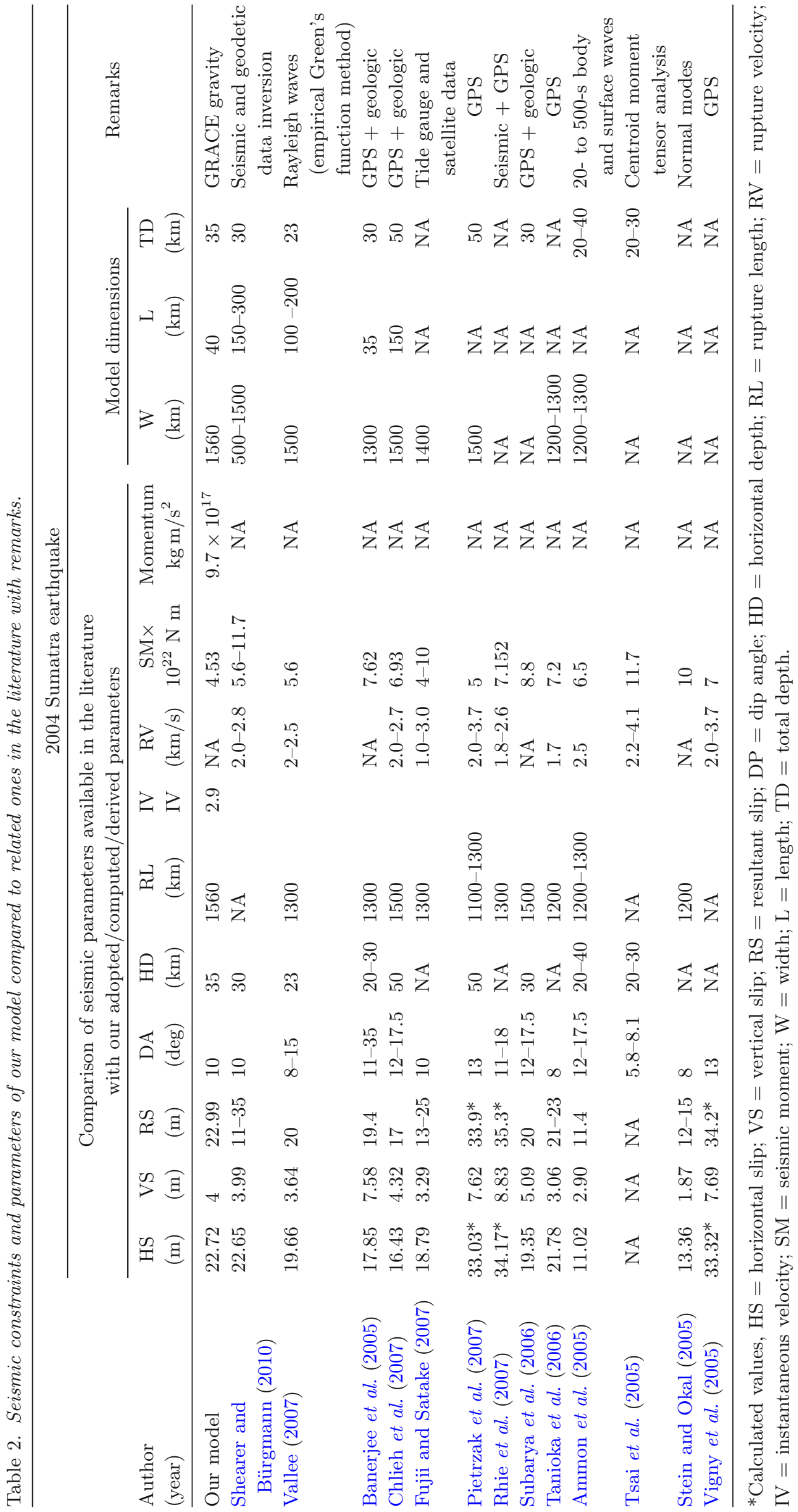


Table 3. Literature support for the choice of our gravity model parameters (density, layer thickness).

\begin{tabular}{l} 
Geophysical constraints for our model \\
\hline Choice of depths and densities of our model \\
\hline Satellite height above msl* \\
Sea surface water layer above msl \\
deformation (first layer)* \\
Water layer from msl to ocean bottom \\
(second layer) \\
Average depth of ocean floor below ms* \\
Deformation of the ocean floor (third \\
layer)*
\end{tabular}

Fourth layer $^{\dagger}$

Fifth layer*

Sixth layer ${ }^{\dagger}$

Seventh layer*

Eighth layer ${ }^{\dagger}$

Ninth layer*

Tenth layer ${ }^{\dagger}$

Eleventh layer*
Published literature

$500 \mathrm{~km}$ (Tapley et al. 2004; Cambiotti and Sabadini 2013).

We independently computed the difference of geoid undulations

$(N=T / \gamma)$ for both pre- and post-earthquake GRACE datasets

(Heiskanen and Moritz 1967; Lambeck 1990), where $T$ and

$\gamma\left(=G M / R^{2}\right)$ are the disturbing potential and normal gravity on spherical Earth, respectively. Broerse et al. (2011) have attempted it through a complicated sea level equation method.

Using Topex (http://topex.ucsd.edu).

Vertical displacement using published GPS literature (Chlieh et al. 2007; Rhie et al. 2007) density (Lowrie 2007; Cambiotti and Sabadini 2013). Choice of density values of second to fifth layers are as per Cambiotti and Sabadini (2013).

Lowrie (2007) and Cambiotti and Sabadini (2013).

To accommodate depth-wise slip distribution in our model, a thin sandwiched layer is considered, which shares the same physical properties (densities) as that of the ninth layer (Lowrie 2007; Cambiotti and Sabadini 2013).

Lowrie (2007) and Cambiotti and Sabadini (2013).

To accommodate depth-wise slip distribution in our model, a thin sandwiched layer is considered, which shares the same physical properties (densities) as that of the ninth layer (Lowrie 2007; Cambiotti and Sabadini 2013).

Lowrie (2007) and Cambiotti and Sabadini (2013).

To accommodate depth-wise slip distribution in our model, a thin sandwiched layer is considered, which shares the same physical properties (densities) as that of the ninth layer (Lowrie 2007; Cambiotti and Sabadini 2013).

Lowrie (2007) and Cambiotti and Sabadini (2013).

To accommodate depth-wise slip distribution in our model, a thin sandwiched layer is considered, which shares the same physical properties (densities) as that of the ninth layer (Lowrie 2007; Cambiotti and Sabadini 2013).
* Gravity effect included in co-seismic gravity modelling.

${ }^{\dagger}$ Gravity effect not included in co-seismic gravity modelling.

to the co-seismic event. Table 2 enlists the seismic constraints and estimated parameter details from the published literature. We also include inferred seismic parameters in table 2. For our 3-D gravity, model inputs cited in table 3 were helpful. We compare our model results with relevant ones from the literature (table 4 ). Table 4 also contains our isolated gravity responses both at msl and satellite height and crucial co-seismic 3-D gravity response details of relevant source layers (figure 2). Thus, table 4 clarifies several issues connected with the size of co-seismic anomalies, modelling aspects and accrued results thereof.
In figure 1, we include isolated GRACE gravity anomaly, our forward gravity response and a vertical projection of our gravity model (ABFE, Down-going block, EFCD, Up-thrown block and $\mathrm{EF}$, fault trace) in the background tectonic framework of the Sumatra earthquake 2004. It is to be noted that the RMS error of $0.06257 \mu$ gal $(6.26 \%)$ between our forward gravity response and observed (isolated) anomaly reflects a reasonably good match. Figure 2 is a schematic explanation of our 11-layered 3-D gravity model showing a depth-wise change in dip thrust and we mention all relevant coordinates of pyramid corners 

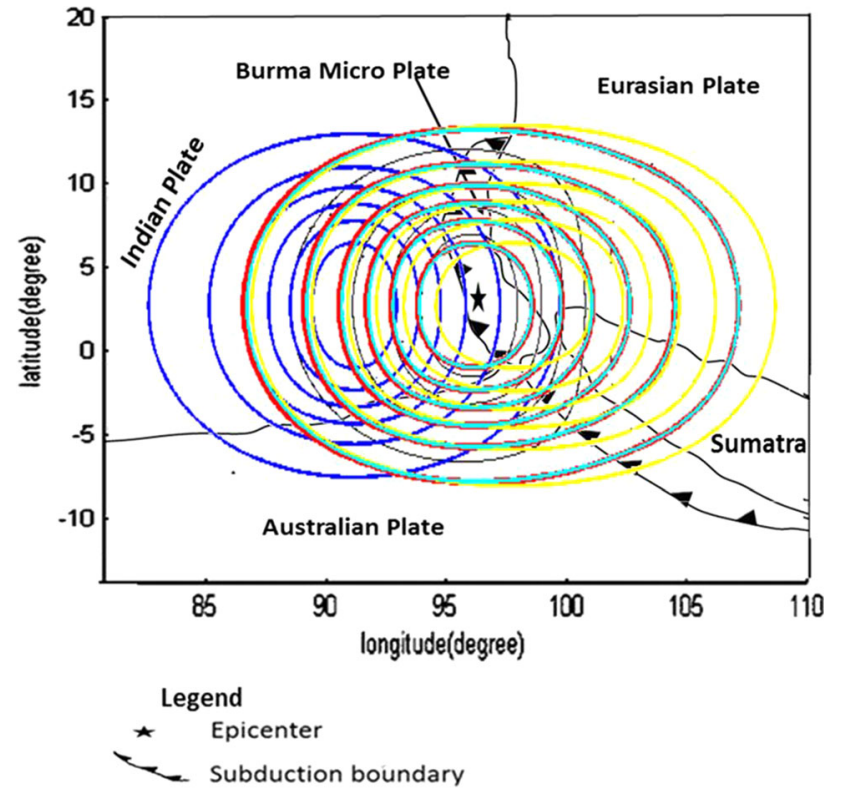
(a) $\bigcirc$ First layer (water layer)
(b) Third layer (Ocean floor)
(c) Fifth layer

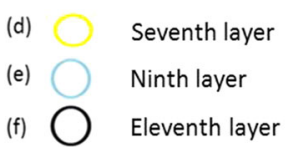

Figure 3. Gravity responses ( $\mu$ gal) of six layer (layers included in co-seismic forward gravity modelling) out of our 3-D 11-layered model (figure 2). (a) Water layer (gravity anomaly range $\left((-0.3\right.$ to -0.05$) \times 10^{-7}$ with a contour interval of $\left.-0.05 \times 10^{-7}\right)$ is shown in blue colour. (b) Ocean floor (third layer) (gravity anomaly range -2.5 to -0.05 with a contour interval of -0.05 ) is shown in green colour. (c) Fifth layer (gravity anomaly values $0.2-2.0$ ), with a contour interval of -0.2 ) is shown in red colour. (d) Seventh layer (gravity anomaly values $(-1.2$ to -0.2 , with a contour interval of -0.2 ) are shown in yellow colour. (e) Ninth layer (gravity anomaly values $0.1-1.1$ with a contour interval of 0.1 ) is shown in light blue colour. (f) Eleventh layer (gravity anomaly values $(0.05-0.40)$, with a contour interval of 0.05 ) is shown in black colour.

and densities of different layers in the caption. In figure 3 , we present the individual forward responses of all relevant six density interfaces (layers included in co-seismic forward gravity modelling) in a superimposed manner with different colours. Their combined response constitutes the total model response already shown in figure 1 . Our gravity inferred average instantaneous velocity, minimum rupture length, seismic moment and momentum are, respectively, $2.9 \mathrm{~km} / \mathrm{s}, 1560 \mathrm{~km}$, $4.53 \times 10^{22} \mathrm{Nm}$ and $9.7 \times 10^{13} \mathrm{~kg} \mathrm{~m} / \mathrm{s}$. These seismological parameters match well with respective values in the literature (Lay et al. 2005; Engdahl et al. 2007; Katsumata 2015). The computed momentum corresponds to an area pulse at ocean bottom that led to tsunami generation.

\subsection{GRACE satellite gravity processing and our forward gravity model}

It is to be noted that our current GRACE gravity data processing is similar to that of Sastry and Sonker (2017). Co-seismic gravity signal (table 1) separation is simple and straightforward and the resulting gravity anomaly pattern conforms to thrust fault environment associated with the subduction process at ocean bottom (Sibuet et al. 2007; Broerse et al. 2011). Our 3-D thrust fault gravity model (figure 2) has a rupture length of $1560 \mathrm{~km}$ (Sibuet et al. 2007) with a vertical slip of $4 \mathrm{~m}$ and a dip angle in the range $8-10^{\circ}$ at ocean bottom (Wang and Liu 2006). This simple model at sea bottom had a forward gravity response amplitude of $-2.5 \mu \mathrm{gal}$ (figure 3 (green contours)) far exceeding the observed satellite gravity anomaly (figure 1 (black contours)). So, we have introduced an 11-layered 3-D thrust fault model, whose details are as follows:

(1) the first layer $\left(1 \times 10^{-6} \mathrm{msl}\right) \mathrm{km}$ is a deformed sea surface,

(2) the second layer (water layer) extends from $\mathrm{msl}$ to $-1.222 \mathrm{~km}$ depth-wise,

(3) the third layer $(-1.222$ to $-1.226 \mathrm{~km})$ coincides with the deformed ocean floor,

(4) the fourth layer corresponds to the oceanic crust $(-1.226$ to $-9.226 \mathrm{~km})$,

(5) the fifth layer (figure 2) extends from -9.226 to $-9.232 \mathrm{~km}$,

(6) the sixth layer extends from -9.232 to $-17.232 \mathrm{~km}$,

(7) the seventh layer extends from -17.232 to $-17.239 \mathrm{~km}$,

(8) the eighth layer extends from -17.239 to $-35.00 \mathrm{~km}$,

(9) the ninth layer extends from -35.00 to $-35.01 \mathrm{~km}$,

(10) the tenth layer extends from -35.01 to $-54.998 \mathrm{~km}$ and

(11) the eleventh layer extends from -54.998 to $-55.000 \mathrm{~km}$.

The gravity responses of co-seismic anomaly causative first, third, fifth, seventh, ninth and eleventh layers are included in figure 3 with respective blue, green, red, yellow, light blue and black contours in an overlapping fashion. The combined response of these (red contours) is shown in figure 1. It closely matches the observed (black contour pattern in figure 1) isolated gravity with an RMS error of $0.06257 \mu$ gal $(6.26 \%)$. It may be 


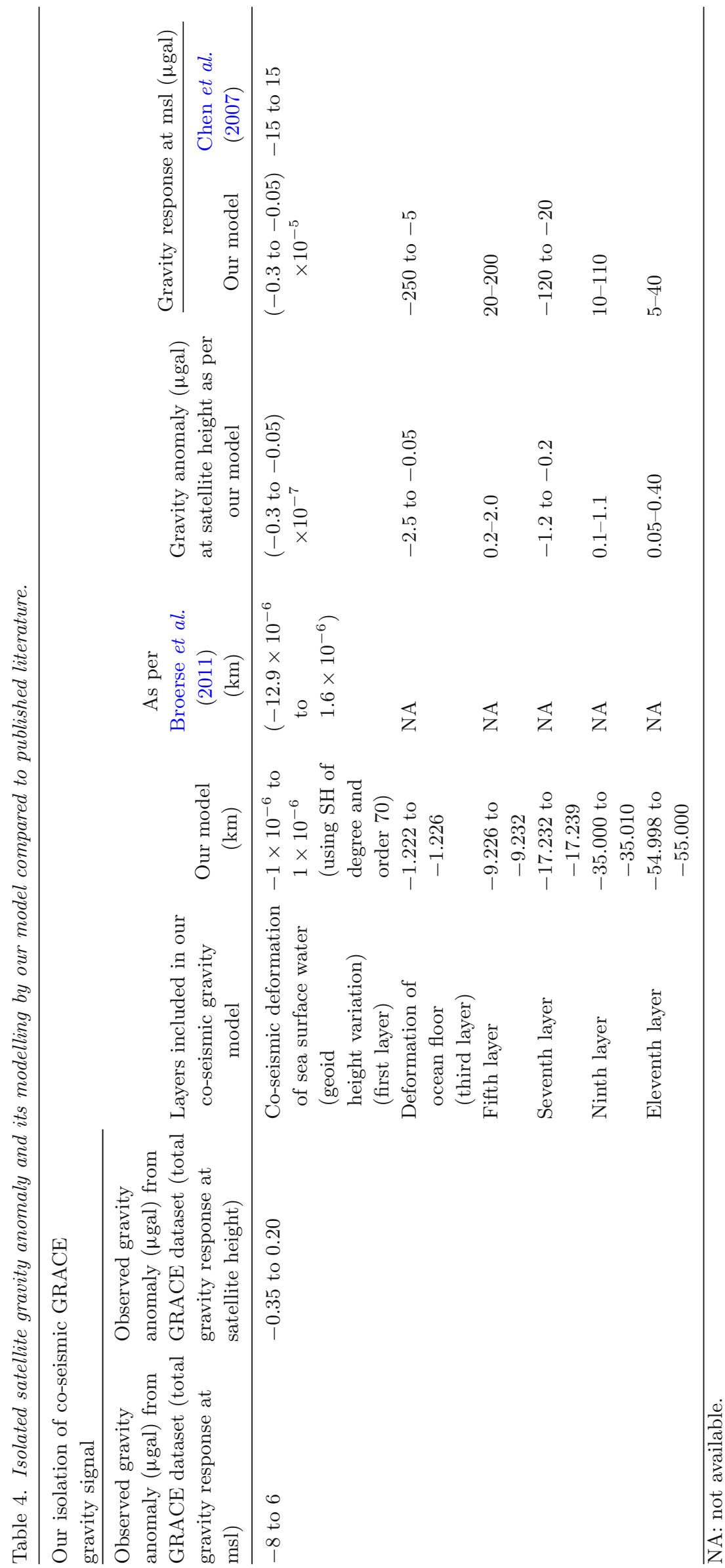


mentioned that 3-D edge effect in forwarding gravity responses at satellite height is noticed only for the eighth layer (figure 2) and it is addressed by a proper singularity removal procedure (Gokula and Sastry 2015a). However, for brevity sake, we are not including those illustrations here.

Our gravity model and its gravity response, respectively, differ from conventional point deformation models (Sun and Okubo 1993) in homogeneous elastic half-space and their gravity response formulations and related studies based on them (Hayes et al. 2006; Cambiotti and Sabadini 2013; Han et al. 2013; Schultz et al. 2016; Harms et al. 2015). Rather, our forward modelling follows a more traditional approach, which involves depthwise density variation and somewhat 'anti-root' concept of Isostasy (Watts 2001).

\subsection{Deformation of top sea level modelling}

Our simple computational method for co-seismic geoidal height deformation yields similar results as that of Broerse et al. (2011, 2014), which is based on a more complex sea level equation that includes the effect of ocean floor deformation.

\subsection{Earlier models vis-à-vis our model}

Our way of honouring co-seismic sea-surface deformation is similar to Sastry and Sonker (2017) and it avoids the complex calculations proposed by Broerse et al. (2011) for gravity effect of displaced ocean water mass based on earlier GRACE datasets (Han et al. 2006; Chen et al. 2007; Panet et al. 2007; de Linage et al. 2009) and earthquake slip models. We have evaluated the co-seismic deformation of the surface water layer based on geoid height computations (table 4). Further, our gravity model (figure 2) and its total response (shown in red colour contours in figure 1) fully account for the observed GRACE gravity anomaly (shown in black colour contours in figure 1). In contrast, Broerse et al. (2011) have only considered the gravity peak positive and negative values variation with depth.

Further, as per Broerse et al. (2011, 2014) horizontal slip had to be much larger in the trench region in comparison to vertical slip. As per our proposed gravity model, the horizontal, vertical and dip slips are, respectively, 22.72, 4 and 22.99 $m$ with dip angles of $10-58^{\circ}$ (figure 2 ). Our RMS error fit of $0.06257 \mu \mathrm{gal}(6.26 \%)$ for computed gravity response to GRACE gravity data is novel to the best of our knowledge.

\subsection{Seismic momentum}

Our gravity derived instantaneous (subject to our isolation of GRACE gravity signal instants) seismic momentum $\left(9.7 \times 10^{17} \mathrm{~kg} \mathrm{~m} / \mathrm{s}\right)$ is novel in relating it to area vector pulse of co-seismic ocean floor deformation that has been communicated to water layer overburden leading to the Sumatra 2004 tsunami. In fact, this area pulse operated like the piston of a large area. Unfortunately, such a parameter (momentum) does not figure in the seismological literature.

\section{Conclusions}

The GRACE satellite gravity response for the 2004 Sumatra earthquake has been isolated by the difference method. Our proposed novel 3-D (11-layered) thrust fault model extends from mean sea level to hypocentre depth and beyond $(55 \mathrm{~km})$. The computed forward response fully characterises the observed (isolated) co-seismic gravity signal for the Sumatra earthquake 2004 (tsunami) source. The RMS error fit of computed gravity response $(0.06257 \mu$ gal $(6.26 \%))$ with isolated GRACE gravity data reflects a close match.

Our model accommodates depth-wise dip slip variation, which conforms to widely held seismological models in the literature for the Sumatra earthquake 2004. Our gravity inferred average instantaneous velocity, minimum rupture length, seismic moment and momentum are, respectively, $2.9 \mathrm{~km} / \mathrm{s}, \quad 1560 \mathrm{~km}, 4.53 \times 10^{22} \mathrm{Nm}$ and $9.7 \times$ $10^{17} \mathrm{~kg} \mathrm{~m} / \mathrm{s}$. These independent estimates of seismological parameters match well with respective ones in the literature. Further, the gravity derived instantaneous seismic momentum corresponds to an area pulse at ocean bottom that has led to tsunami generation.

\section{Acknowledgements}

We gratefully acknowledged the help received from Mr Aruj Pant, a post-graduate student under the first author in isolation of satellite gravity signal of Sumatra earthquake 2004 and Dr Anand Gokula for gravity forward modelling software of right vertical pyramid model. Mr Sonker is thankful to the Ministry of Human Resources Development (MHRD), Government of India, for financial support. 


\section{References}

Ammon C J, Thio J C, Robinson D, Hjorleifsdottir N S, Kanamori V, Lay H, Das T, Helmberger S S, Ichinose D, Polet G and Wald J 2005 Rupture process of the 2004 Sumatra-Andaman earthquake; Science $\mathbf{3 0 8}$ 1133-1139.

Araki E, Shinohara M, Obana K, Yamada T, Kaneda K, Kanazawa T and Suyehiro K 2006 Aftershock distribution of the 26 December 2004 Sumatra-Andaman earthquake from ocean bottom seismographic observation; Earth Planets Space 58 113-119.

Banerjee P, Pollitz F F and Bürgmann R 2005 The size and duration of the Sumatra-Andaman earthquake from farfield static offsets; Science 308 1769-1772.

Barckhausen U 2006 The segmentation of the subduction zone offshore Sumatra: Relations between upper and lower plate; $A G U \mathbf{8 7 ( 5 2 )}$.

Bettadpur S 2007 Product specification document Rev 4.5; GRACE, pp. 327-720.

Briggs R W, Sieh K, Meltzner A J, Natawidjaja D, Galetzka J and Suwargadi B 2006 Deformation and slip along the Sunda megathrust in the great 2005 Nias-Simeulue earthquake; Science 311 1897-1901.

Broerse D B T, Vermeersen L L A, Riva R E M and Vander W 2011 Ocean contribution to co-seismic crustal deformation and geoid anomalies: Application to the 2004 December 26 Sumatran-Andaman earthquake; Earth Planet. Sci. Lett. 305 341-349.

Broerse T, Riccardo R and Bert V 2014 Ocean contribution to seismic gravity changes: The sea level equation for seismic perturbations revisited; Geophys. J. Int. 199 1094-1109.

Cambiotti G and Sabadini R 2013 Gravitational seismology retrieving centroid-moment tensor solution of the 2011 tohoku earthquake; J. Geophys. Res.: Solid Earth 118(1) 183-194.

Cazenave A and Chen J 2010 Time-variable gravity from space and present-day mass redistribution in the earth system, earth planet; Sci. Lett. 2010 7-35.

Chen J L, Wilson C R, Tapley B D and Grand S 2007 GRACE detects coseismic and postseismic deformation from the Sumatra-Andaman earthquake; Geophys. Res. Lett. 34 L13302.

Chlieh M, Avouac J P, Hjorleifsdottir V, Song T R A, Sieh J C, Sladen K, Hebert A, Prawirodirdjo H, Bock L and Galetzka J 2007 Coseismic slip and afterslip of the Great Mw 9.15 Sumatra-Andaman earthquake of 2004; Bull. Seismol. Soc. Am. 97 152-173.

Delescluse M and Chamot-Rooke N 2007 Instantaneous deformation and kinematics of the India-Australia plate; Geophys. J. Int. 168 818-842.

de Linage C, Rivera L, Hinderer J, Boy J P, Rogister Y, Lambotte S and Biancale R 2009 Separation of coseismic and postseismic gravity changes for the 2004 SumatraAndaman earthquake from 4.6 yr of GRACE observations and modelling of the coseismic change by normal-modes summation; Geophys. J. Int. 176 695-714.

De Viron O, Panet I, Mikhailov V, Van Camp M and Diament M 2008 Retrieving earthquake signature in grace gravity solution; Geophys. J. Int. 174 $14-20$.
Engdahl E R, Villaseñor A, De Shon H R and Thurber C H 2007 Teleseismic relocation and assessment of seismicity (1918-2005) in the region of the $2004 \mathrm{Mw} 9.0$ SumatraAndaman and $2005 \mathrm{Mw} 8.6$ Nias Island great earthquakes; Bull. Seismol. Soc. Am. 97 43-61.

Fujii Y and Satake K 2007 Tsunami source of the 2004 Sumatra-Andaman earthquake inferred from tide gauge and satellite data; Bull. Seismol. Soc. Am. 97 S192-207.

Geist E L, Vasily V T, Diego A, Pollitz F F and Bilek S L 2007 Implications of the 26 December 2004 SumatraAndaman earthquake; Bull. Seismol. Soc. Am. 97(1A) S249-S270.

Gilbert F and Backus G 1968 Elastic gravitational vibrations of a radially stratified sphere; In: Dynamics of Structured Solids (ed). Harmann G, ASME, pp. 82-95.

Gokula A P and Sastry R G 2015a Gravitational attraction of a vertical pyramid model of flat top and bottom with depth-wise linear density variation; Curr. Sci. (00113891) 109(10).

Gokula A and Sastry R G 2015b Gravitational attraction of a vertical pyramid model of flat top \& bottom with depth-wise parabolic density variation. J. Earth Syst. Sci. 124(8) 1735-1744.

Han S C, Shum C K, Bevis M and Kuo C Y 2006 Crustal dilatation 103 observed by GRACE after the 2004 Sumatra-Andaman earthquake; Science $\mathbf{3 1 3}$ 658-661.

Han S C, Riva R, Sauber J and Okal E 2013 Source parameter inversion for recent great earthquakes from a decade-long observation of global gravity fields; J. Geophys. Res. 118 1240-1267.

Harms J, Ampuero J P, Barsuglia M, Chassande-Mottin E, Montagner J P, Somala S N and Whiting B F 2015 Transient gravity perturbations induced by earthquake rupture; Geophys. J. Int. 201 1416-1425.

Hayes T J, Tiampo K F and Fernandez J 2006 Gravity changes from a stress evolution earthquake simulation of California; J. Geophys. Res. 111 B09408.

Heiskanen W A and Moritz H 1967 Physical Geodesy; W.H. Freeman, San Francisco.

Heki K and Matsuo K 2010 Coseismic gravity changes of the 2010 earthquake in central Chile from satellite gravimetry; Geophys. Res. Lett. 37 L24306.

Katsumata K 2015 A long-term seismic quiescence before the 2004 Sumatra (Mw 9.1) earthquake; J. Bull. Seismol. Soc. Am. 1051.

Konca A O, Avouac J P, Sladen A, Meltzner A J, Sieh K, Fang P, Galetzka J, Genrich J, Chlieh M, Natawidgaga D H, Bock Y, Fielding E J and Helmberger D V 2008 Partial rupture of a locked patch of the Sumatra megathrust during the 2007 earthquake sequence; Nature 456 631-635.

Lambeck K 1990 Aristoteles - An ESA mission to study the earth's gravity field; ESA J. 14 1-21.

Lay T, Kanamori H, Ammon C J, Nettles M, Ward S N, Aster R C, Beck S L, Bilek S L, Brudzinski M R, Butler R, DeShon H R, Ekström G, Satake K and Sipkin S 2005 The great Sumatra-Andaman earthquake of 26 December 2004; Science 308 1127-1133.

Liu P L F, Woo S B and Cho Y S 1998 Computer Programs for Tsunami Propagation and Inundation; Cornell University, Ithaca, NY, USA. 
Lowrie W 2007 Fundamentals of Geophysics; 2nd edn, Swiss Federal Institute of Technology, Zürich.

Okubo S 1992 Gravity and potential changes due to shear and tensile faults in a half-space; J. Geophys. Res. 97 $7137-7144$.

Panet I, Mikhailov V, Diament M, Pollitz F, King G, De Viron O, Holschneider M, Biancale R and Lemoine J M 2007 Coseismic and post-seismic signatures of the Sumatra 2004 December and 2005 March earthquakes in GRACE satellite gravity; Geophys. J. Int. 171 177-190.

Pietrzak J, Socquet A, Ham D, Simons W, Vigny C, Labeur R J, Schrama E, Stelling G and Vatvani D 2007 Defining the source region of the Indian Ocean Tsunami from GPS, altimeters, tide gauges and tsunami models; Earth Planet. Sci. Lett. 261 49-64.

Plafker G 1972 Alaskan earthquake of 1964 and Chilean earthquake of 1960: Implications for arc tectonics; J. Geophys. Res. 77(5) 901-925.

Poisson B, Oliveros C and Pedreros R 2011 Is there a best source model of the Sumatra 204 earthquake for simulating the consecutive tsunami; Geophys. J. Int. 185 $1365-1378$.

Pollitz F F 1997 Gravity anomaly from faulting on a layered spherical earth with application to central Japan; Phys. Earth Planet. Inter. 99 259-271.

Pollitz F F, Bürgmann R and Banerjee P 2011 Geodetic slip model of the 2011 M9.0 Tohoku earthquake; Geophys. Res. Lett. 38 L00G08.

Rhie J, Dreger D, Burgmann R and Romanowicz B 2007 Slip of the 2004 Sumatra-Andaman earthquake from joint inversion of long-period global seismic wave-forms and GPS static offsets; Bull. Seismol. Soc. Am. 97(1A) S115S127.

Sastry R G and Sonker M K 2017 3-D GRACE gravity model for the 2011 Japan earthquake; J. Earth Syst. Sci. 126(1) $1-4$.

Schultz K W, Sachs M K, Heien E M, Rundle J B, Turcotte D L and Donnellan A 2016 Simulating gravity changes in topologically realistic driven earthquake fault systems: First results; Pure Appl. Geophys. 173(3) 827-838.

Shearer P M and Bürgmann R 2010 Lessons learned from the 2004 Sumatra-Andaman megathrust rupture; Annu. Rev. Earth Planet. Sci. 38 103-131.

Sheriff S D and Stickney M C 1984 Crustal structure of southwestern Montana and east-central Idaho: Results of a reversed seismic refraction line; Geophys. Res. Lett. 11(4) 299-302.

Sibuet J C, Rangin C, Le Pichon X, Singh S, Cattaneo A, Graindorge D, Klingelhoefer F, Lin J Y, Malod J, Maury T, Sultan J L N, Umber M, Yamaguchi H and Sumatra aftershocks team 2007 26th December 2004 great Sumatra-Andaman earthquake: Co-seismic and post-seismic motions in northern Sumatra; Earth Planet. Sci. Lett. 263 88-103.

Sieh K and Natawidjaja D H 2000 Neotectonics of the Sumatran fault; Indones. J. Geophys. Res. 105 28295-28326.

Simons M, Minson S E, Sladen A, Ortega F, Jiang J, Owen S E, Meng L, Am-puero S W and Chu R 2011 The 2011 magnitude 9.0 Tohoku-oki earthquake: Mosaicking the megathrust from seconds to centuries; Science 332 14211425 .

Socquet A, Vigny C, Chamot-Rooke N, Simons W, Rangin C and Ambrosius B 2006 India and Sunda plates motion and deformation along their boundary in Myanmar determined by GPS; J. Geophys. Res. 111 B05406.

Stein S and Okal E A 2005 Speed and size of the Sumatra earthquake; Nature 434 581-582.

Stork A L, Verdon J P and Kendall J M 2014 The robustness of seismic moment and magnitudes estimated using spectral analysis; Geophys. Prospect. 62(4) $862-878$.

Subarya C, Chlieh M, Prawirodirdjo L, Avouac J P, Bock Y, Sieh K, Meltzner A J, Natawidjaja D H and McCaffrey R 2006 Plateboundary deformation associated with the great Sumatra-Andaman earthquake; Nature 440 $46-51$.

Sun W and Okubo S 1993 Surface potential and gravity changes due to internal dislocations in a spherical earth - I, Theory for a point dislocation; Geophys. J. Int. 114 569-592.

Sun W and Okubo S 1998 Surface potential and gravity changes due to internal dislocations in a spherical earth-II, Application to a finite fault; Geophys. J. Int. 132 79-88.

Tanioka Y, Yudhicara, Kususose T, Kathiroli S, Nishimura Y, Iwasaki S I and Satake K 2006 Rupture process of the 2004 great Sumatra-Andaman earthquake estimated from tsunami waveforms; Earth Planets Space $\mathbf{5 8}$ 203-209.

Tapley B D, Bettadpur S, Ries J, Thompson P and Watkins M 2004 GRACE measurements of mass variability in the Earth system; Science 305 503-505.

Tsai V C, Nettles M, Ekstrom G and Dziewonski A M 2005 Multiple CMT source analysis of the 2004 Sumatra earthquake; Geophys. Res. Lett. 32 L17304.

Vallee M 2007 Rupture properties of the giant Sumatra earthquake imaged by empirical Green's function analysis; Bull. Seismol. Soc. Am. 97 S103-S114.

Vigny C, Simons W J F, Abu S, Bamphenyu R, Satirapod C, Choosakul N, Subarya C, Socquet A, Omar K, Abidin H Z and Ambrosius B A C 2005 Insight into the 2004 Sumatra-Andaman earthquake from GPS measurements in southeast Asia; Nature 436 201-206.

Wang X and Liu P L F 2006 An analysis of 2004 Sumatra earthquake fault plane mechanisms and Indian ocean tsunami; J. Hydraul. Res. 44(2) 147-154.

Wang L, Shum C K, Frederik S J, Tapley B and Dail C 2012a Coseismic and postseismic deformation of the 2011 Tohoku-Oki earthquake constrained by GRACE gravimetry; Geophys. Res. Lett. 39 L07301.

Wang L, Shum C K and Jekeli C 2012b Gravitational gradient changes following the Summatra-Andaman earthquake inferred from GRACE; Geophys. J. Int. 191 1109-1118.

Watts A B 2001 Isostasy and Flexure of the Lithosphere; Cambridge University Press, 458p. 